\title{
Oxidation Stability of Conductive Copper Paste Prepared through Electron Beam Irradiation
}

\author{
Received September 1, 2020; revised September 16, 2020; accepted September 28, 2020
}

\author{
Ji Hyun Park ${ }^{\mathrm{a}}$, Chang Woo Kim ${ }^{\mathrm{b}, \mathrm{c}, *}$, and Byung Cheol Lee ${ }^{\mathrm{d}, *}$ \\ ${ }^{a}$ Research and Development Institute, Seoul Radiology Services Co., Ltd., Chungcheongbuk-do 27733, Republic of Korea \\ ${ }^{b}$ Department of Convergence Engineering for Smart and Green Technology, Pukyong National University, Busan 48513 , Republic of Korea \\ 'Department of Graphic Arts Information Engineering, Pukyong National University, Busan 48513, Republic of Korea \\ ¿UNISCAN. Co., Ltd., Seoul 05836, Republic of Korea
}

*Corresponding author E-mail: kimcw@pknu.ac.kr, bclee@uniscan.co.kr

\begin{abstract}
For producing printed electronics, $\mathrm{Cu}$ is an effective material as it overcomes the limitations of traditional noble metals in terms of cost and availability. Hence, this work involved developing a synthesis method for conductive pastes used in printed electronics with electron beam (e-beam) irradiation. Cu nanoparticles with high oxidation stability were prepared by adjusting the absorbed dose of e-beam irradiation. The high stable $\mathrm{Cu}$ nanoparticles, even though exposure to air for 75 days, were used for preparing conductive ink pastes. The electrical conductivity of the $\mathrm{Cu}$ conductive pastes was studied under different sintering conditions. Among the conductive pastes coated on glass substrates under various heat treatment conditions, the paste prepared under the formic acid atmosphere formed a porous, thin film with well-connected particles. Further, we observed that sheet resistance increased as the $\mathrm{Cu}_{2} \mathrm{O}$ volume fraction and crystalline domain size increased. Thus, e-beam irradiation is a suitable process for mass production of conductive nanoparticles owing to its simplicity and fast reaction time.
\end{abstract}

Keywords: Electron beam irradiation, Metal conductive paste, Printed electronics

\section{Introduction}

Methods for fabricating printed electronics have attracted considerable research attention because of their ability to produce flexible electronic devices [1-3]. Traditional electronic devices have been prepared using a broad range of substrates to induce electrical functionalities $[4,5]$. Methods for fabricating electronic devices on bendable and flexible substrates are extremely important owing to their advantages over traditional methods for fabricating electronics [6]. Conventional approaches such as electroless plating, vacuum deposition, and lithography require expensive equipment and harsh processing conditions, and these processes emit toxic wastes owing to the use of highly reactive chemicals [7]. Compared to conventional approaches, printed electronics fabrication methods enable faster production, and they are economical and environmentally friendly. These advantages make such fabrication methods feasible for producing electronic components used in displays, photovoltaics, smart packaging, and sensors.

As a practically employed fabrication method for producing printed electronics, inkjet printing requires a conductive paste with an organic-inorganic composition, including metals, metal oxides, and metal-organic complexes. Inkjet printing allows for roll-2-roll fabrication $[6,8]$. Conductive pastes are generally composed of resins to achieve mechanical and adhesive strength and conductive fillers for providing an electrical path $[7,9]$. Typically, conductive nanoparticles are dispersed in organometallic compounds with conductive polymers. Physicochemical properties of the printed patterns should be measured for determining their conductivity, optical transparency, stability against bending, and adhesion to the substrates $[6,10]$. In particular, the combinations of metals, metal oxides, and resins are important for interconnecting materials in electrically conductive pastes [6]. Because the electrical properties of conductive pastes depend on the amount of solid metallic filler, increasing the metallic filler content results in higher conductivity; however, the other properties of the pastes, such as rheological properties, deteriorate.

Considering the abovementioned requirements, mixtures of micrometer- and nanometer-sized Ag flakes have been widely used as conducting fillers for establishing effective electrical contact among the components of conductive pastes [6,7]. Currently, highly conductive $\operatorname{Ag}\left(\sigma=6.3 \times 10^{7} \Omega^{-1} \cdot \mathrm{m}^{-1}\right)$ particles are the best candidates for conductive inks in industrial applications [10]. Ag nanoparticles fill the pores between Ag microparticles and establish effective electrical connections [10]. Noble metals such as Ag and Au have been studied as conductive fillers in for paste formulation because they show high conductivity and oxidative stability. However, these materials are not suitable for practical applications because of their intrinsically high cost. Therefore, recent studies have evaluated conductive fillers based on non-noble metal alloys for producing conductive pastes. Practically feasible alternative materials that are inexpensive, highly conductive, and exhibit stability during air exposure must be developed.

In current printed electronics, $\mathrm{Cu}$ is an effective conductive material for overcoming the shortcomings of noble metals including cost and availability [11]. From the viewpoint of industrial production, $\mathrm{Cu}\left(\sigma=5.96 \times 10^{7} \Omega^{-1} \cdot \mathrm{m}^{-1}\right)$ is recognized as one of the most promising candidates for conductive fillers because its electrical properties 
including electrical resistivity and thermal conductivity are equivalent to noble metals; moreover, it is inexpensive and suitable for the printed electronics industry [12]. Therefore, various methods for producing $\mathrm{Cu}$ nanomaterials with tailored morphologies and properties have been reported, including photo- and electrodeposition, physiochemical treatments, and wet chemical approaches. Considering the disadvantages and advantages of these methods, a solution-based approach is widely used for ensuring mild synthetic conditions, facile size control, and mass production with low cost. However, when exposed to air, $\mathrm{Cu}$ nanoparticles are easily oxidized, resulting in poor conductivity. In one of the important studies aimed at producing oxidation-resistant $\mathrm{Cu}$ nanoparticles, P. Zhang et al. prepared $\mathrm{Cu}$ nanoparticles with high stability using bis(2-ethylhexyl)amine as the surfactant in the presence of carbon disulfide [13]. J. Li et al. investigated $\mathrm{Cu}$ nanoparticles formed using a water/oleic acid mixed solvent [14]. The morphology of the $\mathrm{Cu}$ nanoparticles was controlled during nucleation, using sodium hypophosphite and oleic acid as the reductant and surfactant, respectively. Spherical $\mathrm{Cu}$ nanoparticles with a size of approximately $30 \mathrm{~nm}$ were obtained. Further, M.P. Pileni et al. [15] used an aqueous dodecyl sulfate solution for reducing $\mathrm{Cu}$ ions. The shapes and sizes of the final products were influenced by the critical micellar concentration.

In the current work, we aimed to fabricate air-stable $\mathrm{Cu}$ nanoparticles for use as conductive metallic fillers through oxidation using electron beam (e-beam) irradiation, without employing any chemical reducing agent. Through controlling the absorbed e-beam dose [16], air-stable $\mathrm{Cu}$ nanoparticles with high stability were prepared for producing conductive ink pastes. The electrical conductivity of the conductive pastes with $\mathrm{Cu}$ nanoparticles prepared under different sintering conditions was studied for determining the relationship between the sheet resistance and $\mathrm{Cu}_{2} \mathrm{O}$ volume fraction depending on the heating temperature.

\section{Experimental details}

\subsection{Preparation of Cu nanoparticles with oxidation stability}

Copper sulfate pentahydrate $\left(\mathrm{CuSO}_{4} \cdot 5 \mathrm{H}_{2} \mathrm{O}, 99.9 \%\right.$, Aldrich) was used as the metal precursor. Ethylene glycol (EG, JUNSEI) and poly(N-vinylpyrrolidone) (PVP, $\mathrm{Mw}=220,000$, JUNSEI) were used as the solvent and dispersing agent, respectively. All chemical reagents were used as such. $\mathrm{Cu}$ nanoparticles were prepared using e-beam irradiation in EG. Typically, $1.7 \mathrm{~g}$ PVP was added to $100 \mathrm{~mL}$ EG at 40 ${ }^{\circ} \mathrm{C}$. Next, we added $0.2 \mathrm{M}$ of copper sulfate to the prepared PVP solution in the presence of $\mathrm{N}_{2}$ gas with stirring for $30 \mathrm{~min}$. The mixture was irradiated with the different absorbed e-beam doses at ambient temperature $\left(20 \sim 25{ }^{\circ} \mathrm{C}\right)$, and the $\mathrm{Cu}$ nanoparticles were synthesized using a batch process. Under e-beam irradiation, the precursor solution was stirred to diffuse the solvated electrons into the reaction mixture. The reacted solution was filtered through centrifugation at 10,000 rpm, treated using formic acid (99\%, Aldrich), and dried at $40{ }^{\circ} \mathrm{C}$ in a vacuum oven. In the current work, e-beam irradiation was carried out in the Korea Atomic Energy Research Institute (KAERI). Under an e-beam energy of $1 \mathrm{MeV}$ and a current of $1 \mathrm{~mA}$, various absorbed doses were produced by the e-beam accelerator.

\subsection{Preparation of conductive paste using Cu nanoparticles as metal fillers}

The as-prepared $\mathrm{Cu}$ nanoparticles through e-beam irradiation were used as metal fillers for producing conductive pastes. Epoxy, acrylic, polyester, and urethane resins were purchased from SK-Cytec and used as binders. Ethyl carbitol acetate, butyl carbitol acetate, triethylene glycol monoethyl ether, and terpineol were purchased from JUNSEI and used as solvents. We swelled $15 \mathrm{wt} \%$ of the binder in $15 \mathrm{wt} \%$ solvent for $30 \mathrm{~min}$ at a rotation of $1,100 \mathrm{rpm}$ and at a revolution of $1350 \mathrm{rpm}$ using a paste mixer (DAEHWA Tech. co., PDM-1KV). The solvent and epoxy binder were mixed with the same $\mathrm{wt} \%$. The mixture was subjected to an antifoaming process at a rotation speed of $100 \mathrm{rpm}$ for $30 \mathrm{~min}$ and a revolution speed of 12,000 rpm using a paste mixer. Then, we added $70 \mathrm{wt} \% \mathrm{Cu}$ nanoparticles and processed the paste using a three-roll mill.

\subsection{Characterization}

The size, morphology, and crystallographic properties of the final samples were characterized using transmission electron microscopy (TEM, JEOL 2200FS), equipped with selected area electron diffraction (SAED). Ultraviolet-visible (UV-vis) analysis was carried out in the range from 200 to $800 \mathrm{~nm}$ with an X-ma 6300PC spectrophotometer (Human Corporation, Korea). The crystalline structure of the final products was characterized using X-ray powder diffraction (XRD). The XRD patterns were recorded in the $2 \theta$ range of $10^{\circ}-80^{\circ}$ with a PHILIPS (Netherlands) X'Pert-MPD diffractometer using $\mathrm{Cu} \mathrm{K}$ a irradiation at 40 and $150 \mathrm{kV}$. The surface oxidation state in the final samples was analyzed using X-ray photoelectron spectroscopy (XPS, Multilab 2000, Thermo Electron Corporation, England). The morphology of sintered $\mathrm{Cu}$ paste film was characterized using scanning electron microscopy (SEM). The resistivity of the paste was measured on a 24203A Source Meter with four-point probes.

\section{Results and discussion}

In the initial step, e-beam irradiation of the aqueous solution generated many active species. Among these active species, the solvated electron $\left(\mathrm{e}_{\text {solv }}\right)$ and hydrogen atom $(\mathrm{H} \cdot)$ act as strong reductive agents [17]. Under e-beam irradiation, $\mathrm{Cu}$ cations were generated in the $\mathrm{CuSO}_{4}$ solution. As the irradiation dose was increased for reducing the $\mathrm{Cu}$ ions, abundant amounts of neutral copper $\left(\mathrm{Cu}_{0}\right)$ atoms were produced through the following reactions:

$$
\begin{gathered}
\mathrm{Cu}^{2+}+2 \mathrm{e}_{\text {solv }}^{-} \rightarrow \mathrm{Cu}_{0} \\
\mathrm{Cu}^{2+}+\mathrm{H} \cdot \rightarrow \mathrm{Cu}_{0}+\mathrm{H}^{+} \\
\mathrm{Cu}^{2+}+\mathrm{Cu}_{0} \rightarrow \mathrm{Cu}_{2}^{2+} \\
\mathrm{Cu}_{\mathrm{m}}{ }^{\mathrm{x}+}+\mathrm{Cu}_{\mathrm{p}}^{\mathrm{y+}} \rightarrow \mathrm{Cu}_{\mathrm{n}}{ }^{(\mathrm{x}+\mathrm{y})+}
\end{gathered}
$$

During irradiation, the $\mathrm{Cu}$ atoms were nucleated and aggregated continuously into clusters. Then, $\mathrm{Cu}$ nanoparticles were grown from the metallic $\mathrm{Cu}$ atom clusters.

$$
\mathrm{nCu}^{0} \rightarrow\left(\mathrm{Cu}^{0}\right)_{\mathrm{n}}(\text { aggregates })
$$

Based on the radiolysis mechanism of EG, the ionization and excitation of EG molecules generated the solvated electrons, and the 

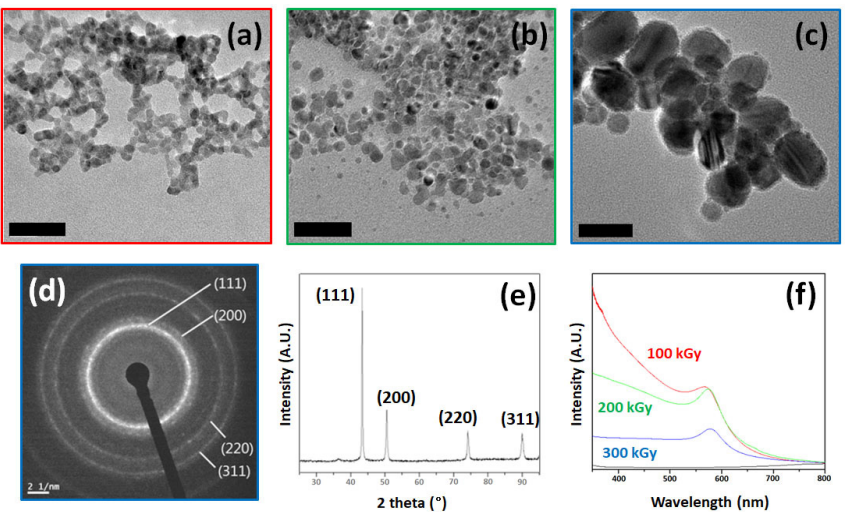

Figure 1. Typical TEM images of $\mathrm{Cu}$ nanoparticles prepared through e-beam irradiation with different absorbed doses (a) $100 \mathrm{kGy}$, (b) $200 \mathrm{kGy}$, and (c) $300 \mathrm{kGy}$. Scale bar is $40 \mathrm{~nm}$. (d) SAED and (e) XRD patterns of Cu nanoparticles formed using $300 \mathrm{kGy}$ of irradiation. (f) UV-vis spectra of Cu nanoparticles with different absorbed doses (red line) $100 \mathrm{kGy}$, (green line) $200 \mathrm{kGy}$, and (blue line) $300 \mathrm{kGy}$.

radical and protonated EG molecules [17]. Three types of reduction species from EG allowed the metal cations to form metallic species.

$$
\begin{gathered}
\left(\mathrm{CH}_{2} \mathrm{OH}\right)_{2} \rightarrow \mathrm{e}^{-},\left(\mathrm{CH}_{2} \mathrm{OH}\right)_{2}{ }^{+} \cdot,\left(\mathrm{CH}_{2} \mathrm{OH}\right)_{2}{ }^{*} \\
\mathrm{e}^{-} \rightarrow \mathrm{e}_{\text {solv }}^{-} \\
\left(\mathrm{CH}_{2} \mathrm{OH}\right)_{2}{ }^{+} \cdot+\left(\mathrm{CH}_{2} \mathrm{OH}\right)_{2} \rightarrow \mathrm{HOH}_{2} \mathrm{CC} \cdot \mathrm{HOH}+\mathrm{HOH}_{2} \mathrm{CCH}_{2} \mathrm{OH}_{2}{ }^{+} \\
\left(\mathrm{CH}_{2} \mathrm{OH}\right)_{2}{ }^{*} \rightarrow \mathrm{HOH}_{2} \mathrm{CC} \cdot \mathrm{HOH}+\mathrm{H} \cdot \\
\mathrm{Cu}_{\mathrm{m}+1}{ }^{+}+\mathrm{HOH} \mathrm{HOH}_{2} \mathrm{COOH} \rightarrow \mathrm{Cu}_{\mathrm{m}+1}+\mathrm{HOH}_{2} \mathrm{CCHOH}+\mathrm{H}^{+}
\end{gathered}
$$

Such a reduction reaction can be conveniently conducted under ambient conditions. During nanoparticle preparation, PVP functioned as the surfactant to control the size and morphologies of the final product.

The TEM images in Fig. 1 show typical morphologies of $\mathrm{Cu}$ nanoparticles prepared from different absorbed doses of e-beam irradiation. The as-prepared $\mathrm{Cu}$ nanoparticles are spherical with sizes ranging from 5 to $47 \mathrm{~nm}$. With an absorbed dose of $100 \mathrm{kGy}$, the size of the $\mathrm{Cu}$ nanoparticles was less than $7 \mathrm{~nm}$, whereas the size increased to $47 \mathrm{~nm}$ as the absorbed dose increased to $300 \mathrm{kGy}$. Thus, microscopic observations indicate that the sizes of the as-prepared Cu nanoparticles increase as the absorbed dose increases. The UV-vis spectra [Fig. 1(f)] of $\mathrm{Cu}$ nanoparticles prepared using different absorbed doses show that the plasmon absorption band of the nanoparticles appears at approximately $570 \mathrm{~nm}$ as the irradiation increases. This band indicates that metal nanoparticles were formed and stabilized by PVP after the metal atoms coalesced during reduction of the $\mathrm{Cu}^{2+}$ cations. Because of their size-dependent optical properties, a red shift in the plasmon absorption of the prepared $\mathrm{Cu}$ nanoparticles implies an increase in the size of the $\mathrm{Cu}$ particles.

The as-prepared $\mathrm{Cu}$ nanoparticles via e-beam irradiation with $300 \mathrm{kGy}$ of the absorbed dose were characterized using SAED and XRD. The four fringes in the SAED pattern of the prepared sample correspond to the (111), (200), (220), and (311) planes in the facecentered cubic (FCC) structure of metallic $\mathrm{Cu}$, thus agreeing with the $\mathrm{XRD}$ results. The XRD patterns of the prepared samples do not contain the peaks for copper oxide. The diffractions angles of 44.28, $50.40,74.12$, and $89.90^{\circ}$ in the XRD patterns correspond to the diffraction angles of the FCC phase (the standard powder diffraction card, ASTM 03-1005). The XRD results show that $\mathrm{Cu}$ metallic nano-
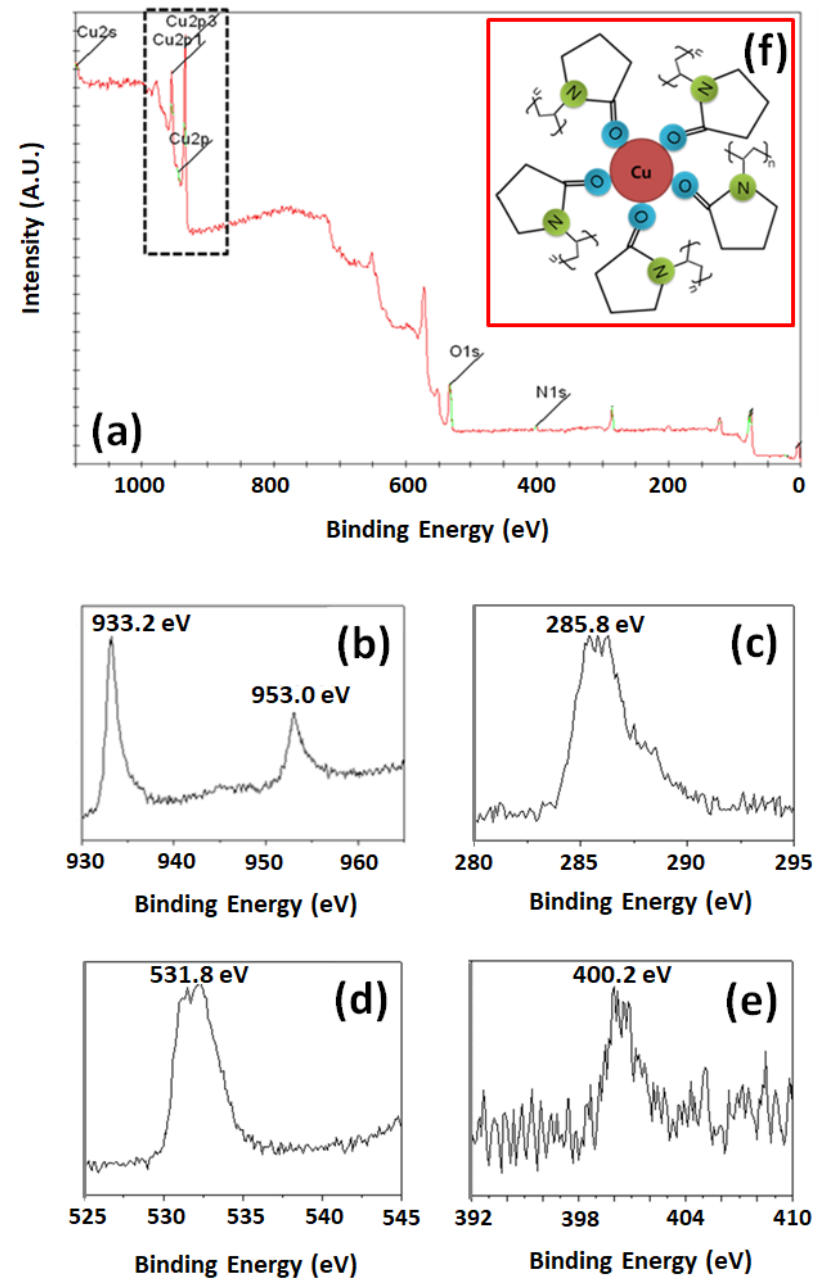

Figure 2. (a) XPS spectra of Cu nanoparticles prepared using $300 \mathrm{kGy}$ of irradiation. (b) Cu2p. (c) C1s. (d) O1s. (e) N1s. (f) illustration of prepared air-stable copper nanoparticles.

particles could be crystallized using e-beam irradiation without employing any chemical reducing agent and special experimental conditions such as high vacuum or high temperature.

In the current work, PVP was used as both the dispersing and capping agent. The surface oxidation state of $\mathrm{Cu}$ nanoparticles prepared using PVP shows the copper $\left(\mathrm{Cu} 2 \mathrm{~s}, \mathrm{Cu} 2 \mathrm{p}_{1 / 2}\right.$, and $\left.\mathrm{Cu} 2 \mathrm{p}_{3 / 2}\right)$, carbon (C1s), oxygen (O1s), and nitrogen peaks (N1s) in the XPS spectra of Fig. 2(a). The XPS spectrum of Cu in Fig. 2(b) shows doublet peaks centered at 933.2 and $953.0 \mathrm{eV}$, corresponding to $\mathrm{Cu} 2 \mathrm{p}_{3 / 2}$ and $\mathrm{Cu} 2 \mathrm{p}_{1 / 2}$ in $\mathrm{CuO}$. The peaks centered at binding energies of 285.8 [Fig. 2(c)], 531.8 [Fig. 2(d)], and $400.2 \mathrm{eV}$ [Fig. 2(e)] correspond to C1s, $\mathrm{O} 1 \mathrm{~s}$, and N1s, respectively, indicating the $\mathrm{C}-\mathrm{C}$ bond, $\mathrm{O} 1 \mathrm{~s}$ in the $\mathrm{C}=\mathrm{O}$ bond, and $\mathrm{C}-\mathrm{N}$ bond. The strong interaction between $\mathrm{Cu}$ and $\mathrm{O}$ in the PVP solution enclosed the surface of the $\mathrm{Cu}$ nanoparticles, indicating chemical adsorption between the metal core and an oxygen atom in PVP as shown in Fig. 2(f). Figure 3 shows the XRD patterns of $\mathrm{Cu}$ nanoparticles after exposure to ambient conditions for 75 days. The XRD patterns of samples obtained after exposure for 75 days period did not show peaks related to oxides. Thus, the prepared $\mathrm{Cu}$ nanoparticles are air-stable. This result reveals that PVP with $\mathrm{Mw}=220,000$ imparted oxidation stability to the formed $\mathrm{Cu}$ nanoparticles during 


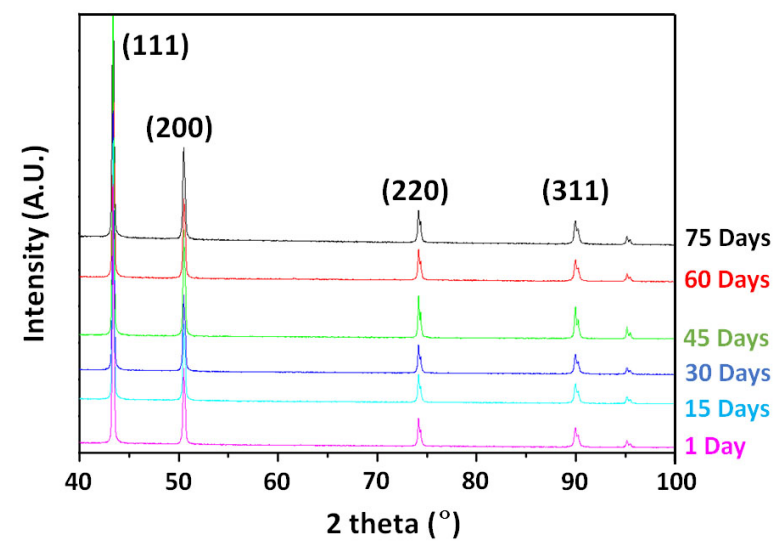

Figure 3. XRD patterns of Cu nanoparticles depending on sintering time.

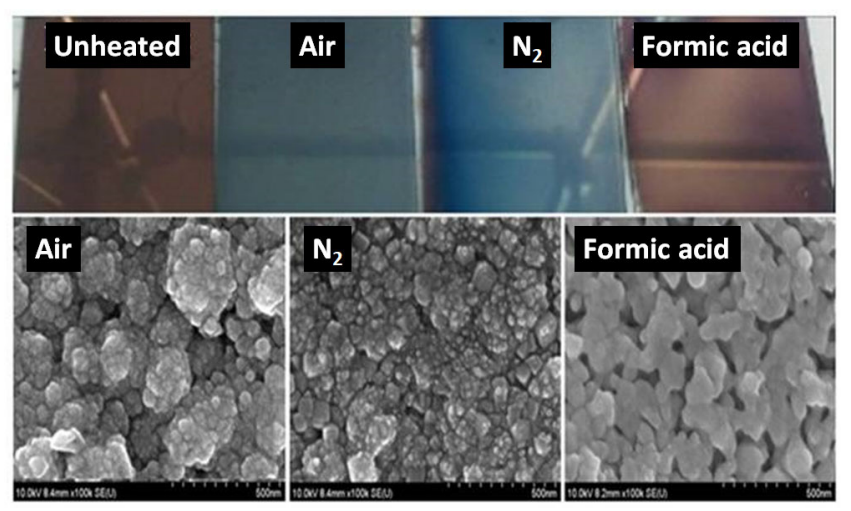

Figure 4. Photograph and top-view SEM image of Cu pastes sintered under different atmospheres.

the nucleation and growth step, with no formation of even a thin oxide layer on the surfaces of the $\mathrm{Cu}$ nanoparticles.

The oxidation resistance and electrical conductivity of the conductive $\mathrm{Cu}$ paste prepared through e-beam irradiation were studied under different sintering conditions, as shown in Fig. 4. A copper paste was printed onto a glass substrate using screen printing and sintered under air, nitrogen gas, and formic acid. Figure 4 shows the changes in the color of the copper paste under the three different sintering atmospheres at $200{ }^{\circ} \mathrm{C}$ for $30 \mathrm{~min}$. The copper paste exposed to air and nitrogen gas changed to a blue color from its original reddish-brown color. Therefore, we can infer that the $\mathrm{Cu}$ paste could undergo oxidation during heat treatment based on its color change. However, the $\mathrm{Cu}$ paste heat-treated under a formic acid atmosphere retains the original reddish-brown color of $\mathrm{Cu}$. SEM images of all the samples were compared for evaluating their morphologies depending on the sintering conditions. The SEM image of the paste heat-treated under air shows typical aggregated nanoparticles. Samples heat-treated under nitrogen show aggregates with smaller particles. Interestingly, a porous, thin film of the $\mathrm{Cu}$ paste on glass after heat treatment under formic acid. In addition, the $\mathrm{Cu}$ nanoparticles were well connected to each other after heat treatment in the formic acid atmosphere. In this work, formic acid provided a reducing atmosphere according to the following reaction.

$$
\mathrm{Cu}_{2} \mathrm{O}+\mathrm{HCOOH} \rightarrow 2 \mathrm{Cu}+\mathrm{H}_{2} \mathrm{O}+\mathrm{CO}_{2}
$$

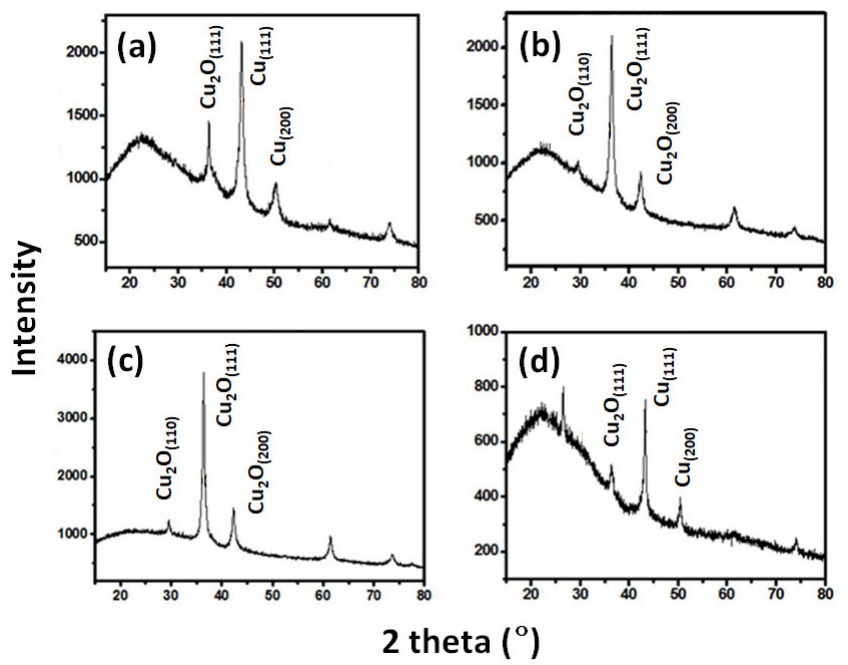

Figure 5. Comparison of typical XRD patterns of (a) as-prepared Cu nanoparticles and Cu pastes sintered under (b) air, (c) nitrogen, and (d) formic acid atmospheres.
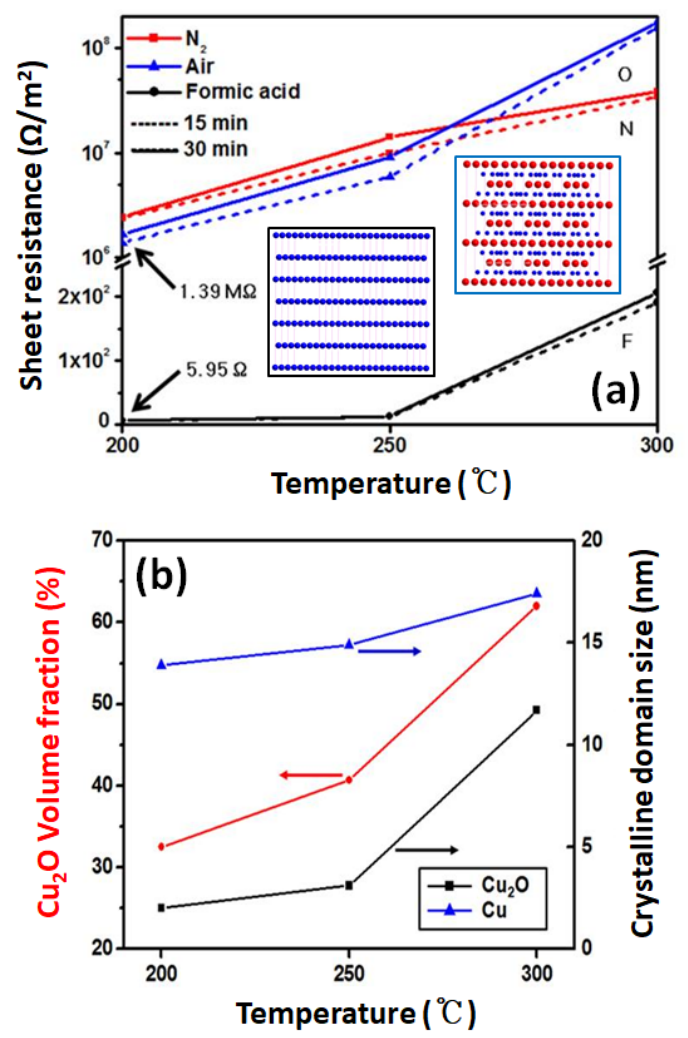

Figure 6. (a) Sheet resistance of $\mathrm{Cu}$ pastes sintered under different atmospheres, sintering temperatures, and durations. Atomic structure (blue ball: $\mathrm{Cu}$ atom, red ball: $\mathrm{O}$ atom) of $\mathrm{Cu}$ metal (black square) and $\mathrm{Cu}_{2} \mathrm{O}$ (red square). (b) Volume fraction and crystalline domain size of Cu paste according to sintering temperature.

As such, unexpected minor oxides generated during formulation of the conductive paste could be reduced. Figure 5 shows the XRD patterns of the heat-treated copper pastes under different atmospheres. The metallic $\mathrm{Cu}$ particles were transformed into $\mathrm{Cu}_{2} \mathrm{O}$ during heat treatment under air or nitrogen gas. However, the $\mathrm{Cu}$ nanoparticles were not oxidized during heat treatment under the formic acid atmo- 
sphere. Therefore, formic acid was effective in preventing oxidation and enabled reduction during sintering.

Figure 6(a) shows the sheet resistance of the sintered $\mathrm{Cu}$ pastes under different atmospheres, sintering temperatures, and sintering times. The sheet resistance increases with temperature and the duration of heat treatment because oxidation occurs on the metal surface. Such a relationship between sheet resistance and sintering conditions was observed in our results. The sheet resistance of the three types of pastes increased as the heating temperature and time increased. The $\mathrm{Cu}$ pastes heat-treated under air and nitrogen gas showed sheet resistances over $1.39 \mathrm{M} \Omega \cdot \mathrm{cm}^{2}$. However, when the paste was sintered for $15 \mathrm{~min}$ at $200{ }^{\circ} \mathrm{C}$ under formic acid, the sheet resistance was $5.95 \Omega \cdot \mathrm{cm}^{2}$. Although the sheet resistance consistently increased as the heating temperature exceeded $250{ }^{\circ} \mathrm{C}$, it is worth noting that $\mathrm{Cu}$ pastes with such sheet resistance values can effectively replace conventional conductive Ag pastes. The volume fractions of the metal and metal oxide in the conductive paste prepared through treatment under formic acid were determined to evaluate the extent of oxidation, as shown in Fig. 6(b). The volume fraction and crystalline domain size of the $\mathrm{Cu}_{2} \mathrm{O}$ phase increased as the temperature and heating duration increased. At a high sintering temperature, the $\mathrm{Cu}$ nanoparticles aggregated with each other and crystal growth occurred in the matrix. Further, the extent of oxidation of the $\mathrm{Cu}$ nanoparticles simultaneously increased in the $\mathrm{Cu}_{2} \mathrm{O}$ crystalline state. Hence, considering the variation trend of sheet resistance with respect to heat treatment, we can conclude that sheet resistance increases as the $\mathrm{Cu}_{2} \mathrm{O}$ volume fraction and crystalline domain size increase.

\section{Conclusions}

In this work, air-stable $\mathrm{Cu}$ nanoparticles were prepared through e-beam irradiation without a chemical reductant. This method is suitable for mass production of nanoparticles owing to its simplicity and fast reaction time. The sizes of the $\mathrm{Cu}$ nanoparticles could be changed by adjusting the absorbed dose of the e-beam irradiation. The oxidation state of the $\mathrm{Cu}$ surface was confirmed through XPS analysis. The XPS results revealed that PVP enabled the synthesis of air-stable $\mathrm{Cu}$ nanoparticles capable of maintaining oxidative stability even after exposure to air for 75 days. The as-prepared $\mathrm{Cu}$ nanoparticles were used as fillers for preparing conductive pastes. Among the $\mathrm{Cu}$ conductive pastes coated on glass substrates under various heat treatment conditions and atmospheres, the paste prepared through heat treatment under formic acid formed a porous, thin film on the glass substrate with well-connected particles. Such structural features show that the prepared $\mathrm{Cu}$ conductive paste can replace conventional conductive pastes prepared from noble metals based on the relationship between the sheet resistance, $\mathrm{Cu}_{2} \mathrm{O}$ volume fractions, and heat treatment conditions.

\section{References}

[1] A. Kamyshny and S. Magdassi, Small. 10, 3515 (2014).

[2] S. Park, M. Vosguerichiant, and Z. Bao, Nanoscale 5, 1727 (2013).

[3] J. L. Wang, M. Hassan, J. W. Liu, and S. H. Yu, Adv. Mater. 30, 1803430 (2018).

[4] Q. Rong, W. Ley, and M. Liu, Chem. Eur. J. 24, 16930 (2018).

[5] A. C. Arias, J. D. MacKenzie, I. McCulloch, J. Rivnay, and A. Salleo, Chem. Rev. 110, 3 (2010).

[6] J. Perelaer, P. J. Smith, D. Mager, D. Soltman, S. K. Volkman, V. Subramanian, J. G. Korvinkdf, and U. S. Schubert, J. Mater. Chem. 20, 8446 (2010).

[7] Y. Zhang, P. Zhu, G. Li, T. Zhao, X. Fu, R. Sun, F. Zhou, and C. Wong, ACS Appl. Mater. Interfaces. 6, 560 (2014).

[8] J. Perelaer, C. E. Hendriks, A. W. M. de Laat, and U. S. Schubert, Nanotechnology 20, 165303 (2009).

[9] Y. Li, K. Moon, and C. P. Wong, Science 308, 1419 (2005).

[10] Y. Zhang, P. Zhu, G. Li, Z. Cui, C. Cui, K. Zhang, J. Gao, X. Chen, G. Zhang, R. Sun, and C. Wong, ACS Appl. Mater. Interfaces. 11, $8382(2019)$.

[11] J. S. Yu, S. H. Kim, M. T. Man, and H. S. Lee, Appl. Sci. Converg. Technol. 27, 75 (2018).

[12] Y. Wang and Z. Yin, Appl. Sci. Converg. Technol. 28, 186 (2019).

[13] G. B. Yang, Z. M. Zhang, S. M. Zhang, L. G. Yu, and P. Y. Zhang, Mat. Res. Bull. 48, 1716 (2013).

[14] J. Wen, J. Li, S. Liu, and Q. Y. Chen, Colloids and Surfaces A: Physicochem. Eng. Aspects 373, 29 (2011).

[15] I. Lisiecki, F. Billoudet, and M. P. Pileni, J. Phys. Chem. 100, 4160 (1996).

[16] B. H. Kim, J. H. Han, S. H. Kwon, and Y. J. Yoon, Appl. Sci. Converg. Technol. 27, 149 (2018).

[17] B. Soroushian, I. Lampre, J. Belloni, and M. Mostafavi, Radiat. Phys. Chem. 72, 111 (2005). 